\title{
Nano-Engineered Environment for Nerve Regeneration: Scaffolds, Functional Molecules and Stem Cells
}

\author{
Liumin $\mathrm{He}^{1,2}$, Lingling Tian ${ }^{5}$, Yuqiao Sun ${ }^{1}$, Yongnu Zhang ${ }^{1}$, Wei Xue ${ }^{1}$, Kwok-Fai So ${ }^{3,4}$, \\ Seeram Ramakrishna ${ }^{4,5, *}$ and Wutian $\mathrm{Wu}^{2,4, *}$
}

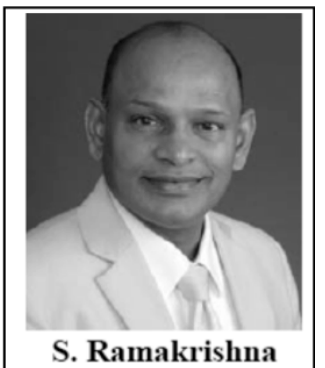

${ }^{I}$ Department of Biomedical Engineering, College of Life Science and Technology, Jinan University, Guangzhou 510632, China; ${ }^{2}$ Department of Anatomy and ${ }^{3}$ Department of Ophthalmology, Li Ka Shing Faculty of Medicine, The University of Hong Kong, Pokfulam, Hong Kong SAR, China; ${ }^{4}$ GuangdongHongkong-Macau Institute of CNS Regeneration (GHMICR), Jinan University, Guangzhou 510632, China; ${ }^{5}$ Center for Nanofibers and Nanotechnology, Department of Mechanical Engineering, Faculty of Engineering, National University of Singapore, 9 Engineering Drive 1, Singapore 117576, Singapore

\begin{abstract}
One of the most complex systems in the human body is the nervous system, which is divided into the central and peripheral nervous systems. The regeneration of the CNS is a complex and challenging biological phenomenon hindered by the low regenerative capacity of neurons and the prohibition factors in response to nerve injuries. To date, no effective approach can achieve complete recovery and fully restore the functions of the nervous system once it has been damaged. Developments in neuroscience have identified properties of the local environment with a critical role in nerve regeneration. Advances in biomaterials and biomedical engineering have explored new approaches of constructing permissive environments for nerve regeneration, thereby enabling optimism with regard to nerve-injury treatment. This article reviews recent progress in nanoengineered environments for aiding nerve-injury repair and regeneration, including nanofibrous scaffolds, functional molecules, and stem cells.
\end{abstract}

Keywords: Electrical stimulation, functional molecules, nanoscaffolds, nerve-tissue engineering, stem cells.

\section{INTRODUCTION}

The nervous system, which governs sensation, movement, and motor coordination, is the most complex organ system of the human body. Various neural injuries can be caused by primary damage, such as thermal, mechanical, chemical, or pathological etiologies, or the secondary damage caused by hypoperfusion, ischemia, and inflammation [1]. Failure to restore these damaged nerves can result in various nervous dysfunctions, such as the loss of muscle function, impaired sensation, and painful neuropathies in the peripheral nervous system (PNS). Permanent functional deficits in the central nervous system (CNS) include paralysis, permanent disability, persistent vegetative states, coma, or even death. These types of damages may cause various anatomic disruptions, including crushed or transected the nerve tracts, interrupted communication between nerve axons and their targets/supporting cells, and the disruption of the bloodbrain barrier; these events are reviewed elsewhere [2-5]. Injuries of the nervous system are generally problematic and intractable because of the complexity of the pathophysiological responses. To date, a clinically effective approach

\footnotetext{
*Address correspondence to these authors at the Guangdong-HongkongMacau Institute of CNS Regeneration (GHMICR), Jinan University, Guangzhou 510632, China; Tel: 65-65162216;

E-mail: seeram@nus.edu.sg (Seeram Ramakrishna)

Tel: 852-28199187; Fax: 852-28170857;

E-mail:wtwu@hkucc.hku.hk (Wutian Wu)
}

has not been developed for the prevention of injury development; functional recovery after nerve injury remains a clinical challenge. Significant efforts have been made to obtain a clearer understanding of the pathophysiology of the nervous system and its local repair mechanisms. The key concept behind nerve injury therapy is that the regenerated axons must penetrate the injury milieu, regrow to the distal nerve trunk, and reestablish functional connections with their targets [6]. The local environment is one of the most critical factors for nerve regeneration. Developments in nanotechnology have allowed the creation of extracellular microenvironments that favor nerve growth. As elaborated in Fig. (1), these microenvironments include nanofibrous structures, tailored presentation of functional molecules, and stem cells. These conditions have been investigated to engineer a favorable local environment for nerve regeneration. However, the mechanism for regulating nerve-cell behavior and growth greatly varies. Thus, a review of recent progress in nanoengineered environments for nerve regeneration is necessary.

\section{BIOMATERIAL AND NANOFIBROUS SCAF- FOLDS FOR NERVE REGENERATION}

\subsection{Nanofibrous Scaffolds Applied in Nerve Tissue Engi- neering}

In the native state, all cells are surrounded by an interlocking mesh of fibrillar extracellular matrix (ECM) proteins with diameters ranging from $50 \mathrm{~nm}$ to $500 \mathrm{~nm}$. The ECM 


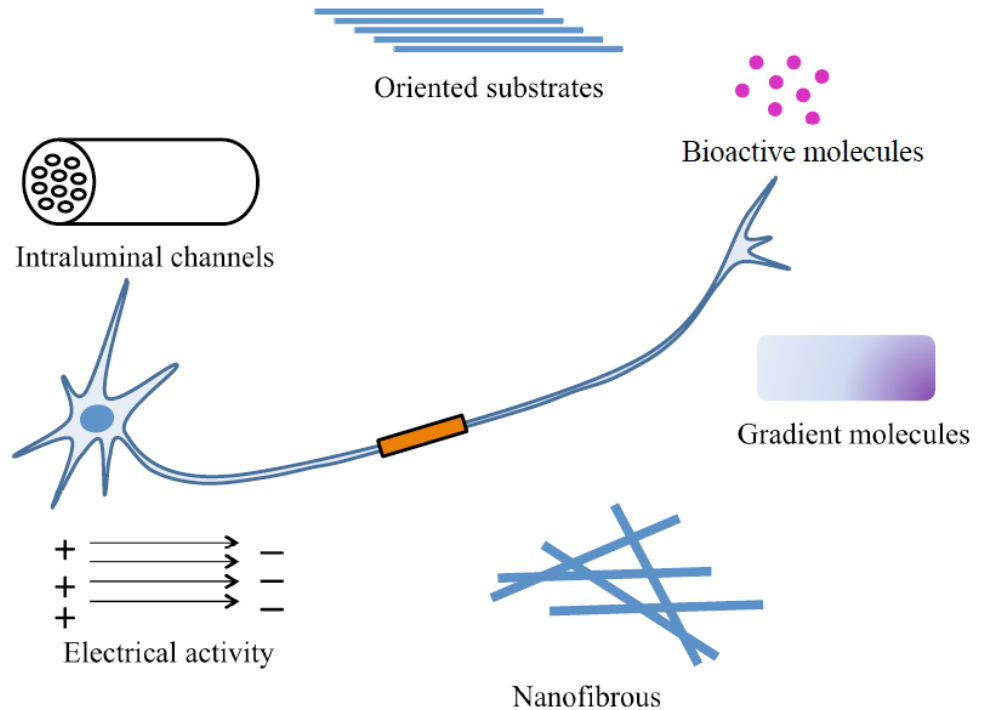

Fig. (1). Schematic illustration of various modes of engineered environments for nerve regeneration.

provides structural support to resident cells and is vital in regulating cellular dynamic behavior. Three processing techniques are commonly used to fabricate ECM-like structures, namely, electrospinning, the self-assembly of peptides/peptide amphiphiles (PAs), and thermally induced phase separation (TIPS). To date, several papers have been published on these three techniques [7-10]. In this paper, we focus on the progress in regulating neural cell behaviors by creating a nanofibrous environment.

Cellular adhesion is essential in maintaining a multicellular structure. Moreover, cell-substrate adhesion appears to be critical during the in vivo synthesis of organs (induced regeneration). Scaffolds with larger specific surface area are generally known to enhance cell adhesion, which is directly related to protein adsorption [11-14]. Most of the cell culture medium is supplemented with serum, which provides sufficient nutrients for cell adhesion, proliferation, differentiation, and other cell behaviors. The specific surface area of a fibrous scaffold is determined by the fiber diameter $[15,16]$. Therefore, nanofibers show better performance in supporting cellular adhesion over microfibrous scaffolds [17]. Furthermore, the rate of neural stem cell differentiation is higher on nanofibers than that on microfibers [18]. Wang et al. [19] showed that collagen nanofibers could cause a $30 \%$ increase in cell proliferation compared with a collagen-coated surface. Furthermore, their data showed that $\beta 1$ integrin interacts with collagen nanofibers and activates extracellular signal-regulated protein kinases 1 and 2 (ERK1/2), which consequently modulate cyclin D1 and cyclin-dependent kinase 2 expression and control cell cycle progression [19]. Joghataei's study indicated of higher survival and differentiation of mesenchymal stem cells into motor neuron-like cells on the PCL/collagen nanofiber scaffold than cultured cells in the TCP and PCL groups [20].

\subsubsection{Nanofibrous Scaffolds by Electrospinning}

Electrospinning is a versatile method to produce nanofibers with various morphologies, such as random nanofibers, aligned nanofibers, core-shell nanofibers, and hollow nanofibers (Fig. 2).
Material choice has a vital role in ensuring the success of neural regeneration. Numerous biomaterials have been electrospun for neural tissue engineering; these materials include synthetic polymers, such as poly(L-lactic acid) (PLLA), polycaprolactone (PCL), poly(3-hydroxybutyrate) (PHB), polydioxanone (PDS), natural polymers, such as chitosan (CS), gelatin (Gel), and silk fibroin (SF), and their composites, such as PCL-Gel and PCL-collagen. Synthetic polymers are generally advantageous because of their attractive properties, such as their controllable biodegradability, biocompatibility, and good processing performance. By contrast, natural macromolecules offer significant advantages in presenting the biological activity and avoiding toxic effects. Therefore, an effective strategy is to use composites of synthetic polymers and natural molecules [22-25].

Fiber diameter is an important factor which could greatly affect cell behaviors. Fiber diameters can be easily tailored by regulating various processing parameters of electrospinning, such as the polymer molecular weight, solution properties (e.g., concentration, viscosity, surface tension, and conductivity), flow rate, electric potential, and the distance between capillary and collector $[15,16,18,26]$. The fiber diameter could significantly affect neural stem/progenitor cell differentiation and proliferation. Christopherson et al. [27] found that the degree of proliferation and cell spreading increased with decreased fiber diameter when rat hippocampus-derived adult NSCs were cultured on laminin-coated electrospun polyethersulfone fibers with average diameters of $283 \pm 45,749 \pm 153$, and $1452 \pm 312 \mathrm{~nm}$. Moreover, 749 $\mathrm{nm}$ diameter fibers favored neuronal differentiation, whereas fibers with diameters of $283 \mathrm{~nm}$ favored oligodendrocyte differentiation. Our previous study [16] indicated that neural stem cells exhibited higher viability and proliferation on 350 and $1150 \mathrm{~nm}$ diameter fibers than on 545 and $746 \mathrm{~nm}$ diameter fibers; longer neurites were also found on fibers with smaller diameters. Wang et al. [28] studied the viability and neuronal differentiation of neural precursors derived from human embryonic stem cells on Tussah SF (TSF) scaffolds with diameters of 400 and $800 \mathrm{~nm}$; fibers of smaller diameter showed better performance in terms of cell viability, 


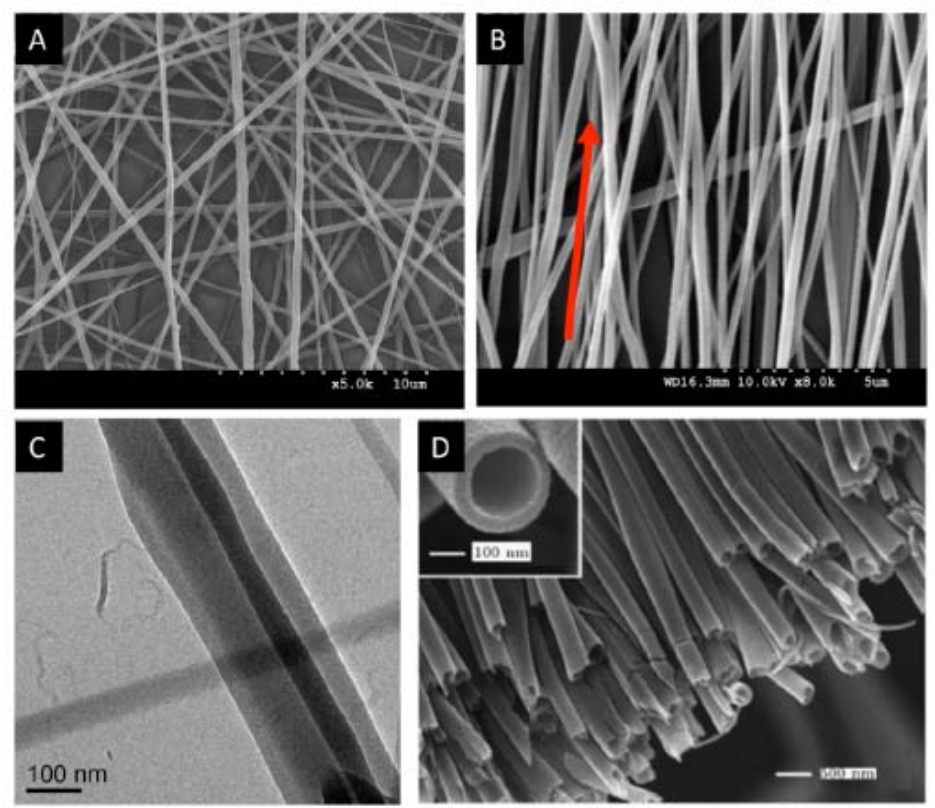

Fig. (2). Nanofibers with various morphologies produced by electrospinning method. (A) random nanofibers; (B) aligned nanofibers; (C) core-shell nanofibers; and (D) hollow nanofibers. (A), (B) and (C) are contributions from the Center of Nanofibers \& Nanotechnology at NUS (NUSCNN), and (D) reprinted with permission from [21]. Copyright (2004) American Chemical Society.

neuronal differentiation, and neurite outgrowth. Recent reports on the effects of fiber diameter on cell behavior are summarized in Table 1. Data from Table 1 indicate that environments fabricated using fibers with small diameters appear to favor nerve-cell adhesion and proliferation because of the large specific surface for protein adsorption and cell-matrix contact. Meanwhile, fibers with relatively smaller diameters may be more flexible and pliable than fibers of larger diameter for cell migration [29], as well as for cell migration and actin filament formation [27]. However, a small mesh size is obtained when the diameter of the electrospun fibers is reduced [16], which consequently suppresses nutrient infiltration and cell ingrowth. Other than the fiber diameter, the fiber pattern has great influence on nerve-cell growth. Aligned fibers can induce nerve cells to elongate along the direction of fiber long axis, resulting in longer neurites. This trend indicates that nerve growth can be potentially regulated and guided by engineering microenvironments containing anisotropic fibers, which will be discussed in the succeeding parts of this article.

\subsubsection{Nanofibrous Scaffolds by TIPS}

The nanofibrous scaffolds are normally produced by electrospinning in two dimensional forms. By contrast, 3D nanofibrous scaffolds can be easily prepared by TIPS from crystalline polymers [30]. In the study of Yang et al., [15] NSCs can progressively grow, migrate and differentiate into neurons throughout a PLLA 3D scaffold fabricated by TIPS. Moreover, multi-channel conduits can be prepared by combining low-pressure injection molding and TIPS, thereby showing great potential applications in nerve-tissue engineering [31, 32]. However, polymer crystallization in the liquid solvent during phase separation is the precondition to prepare nanofibrous scaffolds. Poor polymer availability limits its application. Another drawback involved is the dense structure after solvent exchange, which would prevent cell migration within the scaffolds. Porogen materials [11], which are usually inorganic salts, and multiple solvent systems [12] can be incorporated to create macro/microporous architectures with large pores (Fig. 3).

\subsubsection{Nanofibrous Scaffolds by the Self-Assembly of Pep- tides}

Nanofibrous scaffolds fabricated from self-assembled peptides/PAs macroscopically form highly hydrated 3D gels that can hold large amounts of water; thus, engineering a $3 \mathrm{D}$ analogue of a native ECM microenvironment is favorable. Despite the architectural support, nanostructures can also exhibit biological signals that are recognized by receptors and bioactive extracellular protein domains. These signals are generated through simple modification of the peptide amino acid sequence at a high density. Zhang et al. [33] designed and developed a number of amphiphilic oligopeptide self-assembly systems that consist of alternating positively and negatively charged residues that are separated by hydrophobic residues. The oligopeptide solution RADA16 (RADARADARADARADA, where $\mathrm{A}$ is alanine, $\mathrm{D}$ is aspartic acid, and $\mathrm{R}$ is arginine) rapidly changes into a hydrogel when exposed to physiological media or a salt solution. The resultant hydrogel can support neuronal cell attachment, differentiation, and extensive neurite outgrowth. Furthermore, the scaffolds were found to provide a permissive environment for functional synapse formation between the attached neurons [34]. Our previous study [35] indicated that transplanted neural progenitor cells and Schwann cells could survive, migrate, and differentiate within the RADA16 hydrogels in vitro and in vivo. Robust host cell migration, blood vessel growth, and attachment of axons to the scaffolds were demonstrated [35]. To date, the RADA16 hydrogel is documented to be a promising material in the reconstruction of injured brains [36], the facilitation of functional regeneration of PNS injury [37], and the restoration of visual function 
Table 1. Effects of polymers, electrospun fiber diameter and pattern on nerve cell behaviors.

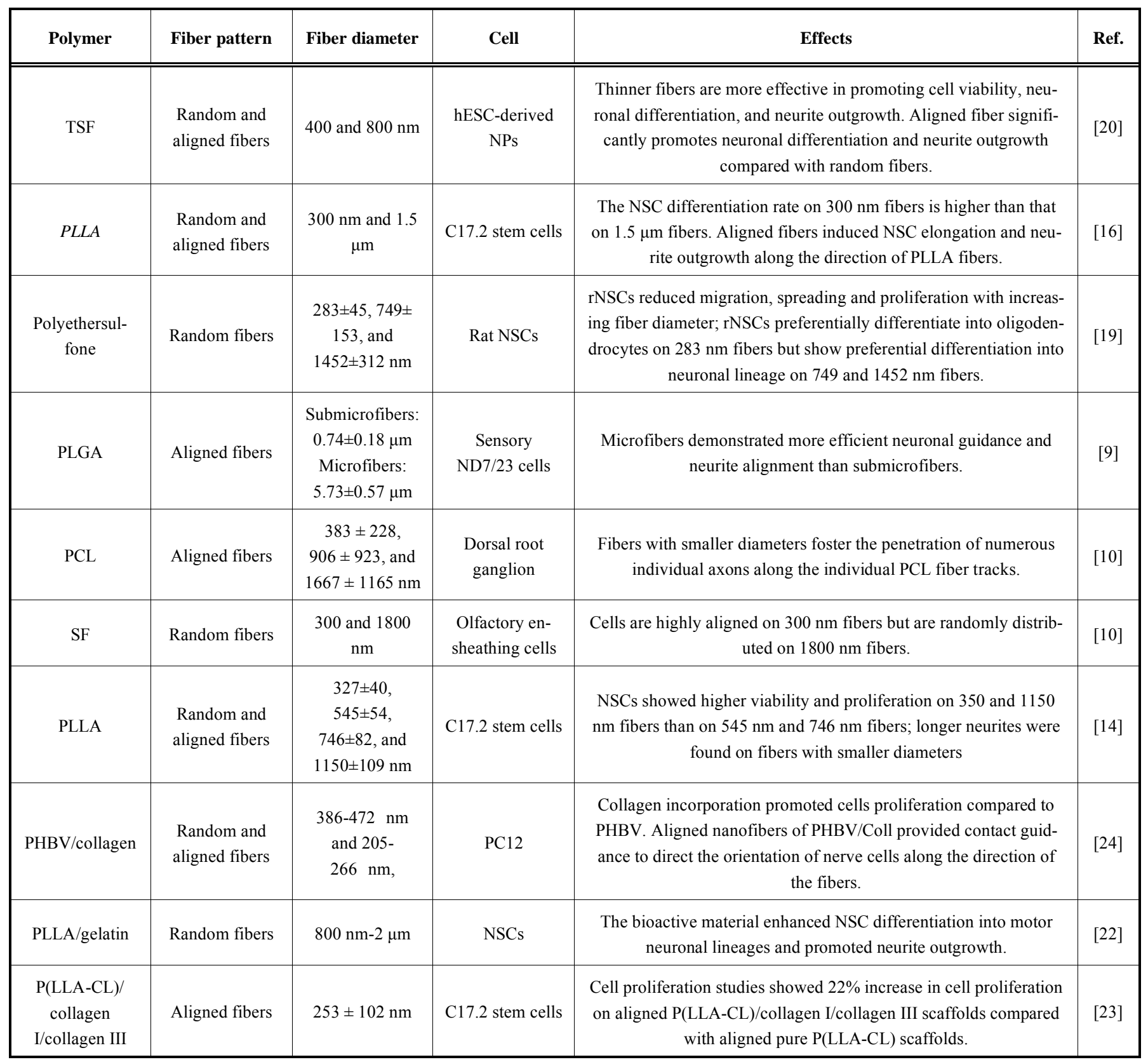

[38]. In addition, neural functions can be stimulated by incorporating a short biofunctional epitope, such as Arg-GlyAsp (RGD), Tyr-Ile-Gly-Ser-Arg (YIGSR), and Ile-Lys-ValAla-Val (IKVAV), in the self-assembling oligopeptide to provide biological cues for neural cell adhesion and differentiation in vitro $[39,40]$ and in vivo and to enhance the reconstruction of injured brains [41].

Stupp's group $[42,43]$ develops a series of PAs that typically contain a peptide sequence and a non-peptidic hydrophobic segment, which is usually an alkyl segment. Both segments are covalently linked by a high-propensity $\beta$ domain to form $\beta$ sheets between the peptide regions of a molecule. Specific motifs are particularly favorable for neural cell attachment and neurite outgrowth; these motifs can be grafted and exposed on the surface of the resultant nanofibers at a high density. For example, RGD, YIGSR, and IKVAV can be grafted onto PA molecules at nearly van der Waals density [45]. The nanofiber hydrogel formed from self-assembly of IKVAV PAs were shown to promote neuron adhesion and neurite sprouting [46]. Moreover, IKVAV PAs induced rapid differentiation of neural progenitor cells into neurons but inhibit the development of astrocytes. The amplification of bioactive epitope presentation to cells on nanofibers accounts for the rapid selective differentiation [47]. However, aqueous solutions of PAs that contain acidic amino acids generally show significantly low $\mathrm{pH}(\sim 3$ to 4$)$, which damages the host tissue or the transplanted cells. Neutralization treatments should be performed to achieve neutral $\mathrm{pH}[35,45]$. Niece et al. [45] described a new self-assembly 

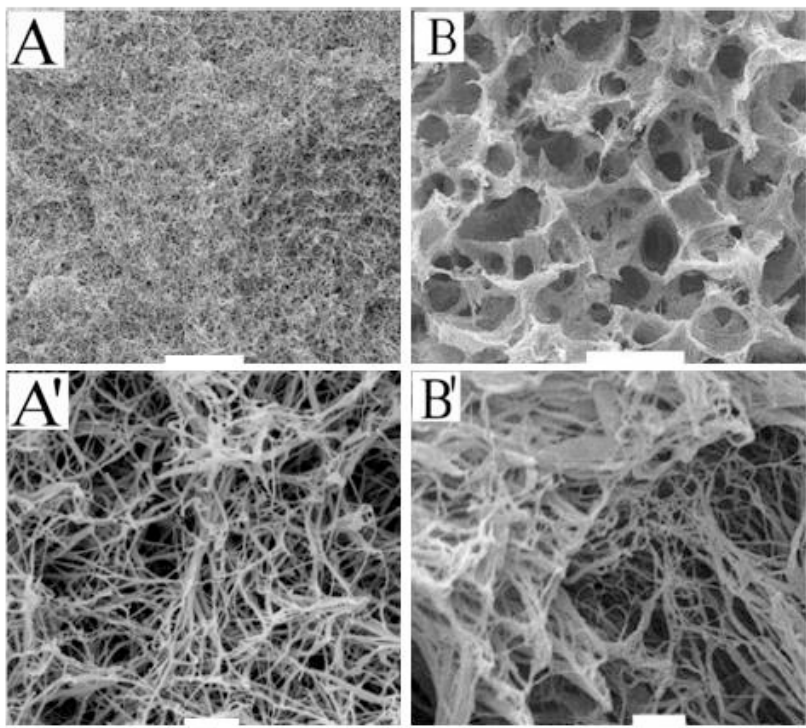

Fig. (3). PLLA porous scaffolds with nanofibers prepared from $5 \%(\mathrm{w} / \mathrm{v})$ PLLA/THF solution at a gelation temperature of $-30{ }^{\circ} \mathrm{C}\left(\mathrm{A}, \mathrm{A}^{\prime}\right)$ and $5 \%(\mathrm{w} / \mathrm{v})$ PLLA in 88/12 dioxane/water at a gelation temperature of $12{ }^{\circ} \mathrm{C}$. Scale bar in $\mathrm{A}, \mathrm{B}=50 \mathrm{~mm} ; \mathrm{A}^{\prime}, \mathrm{B}^{\prime}=2 \mathrm{~mm}$ reprinted from [12], Copyright (2009), with permission from Elsevier.

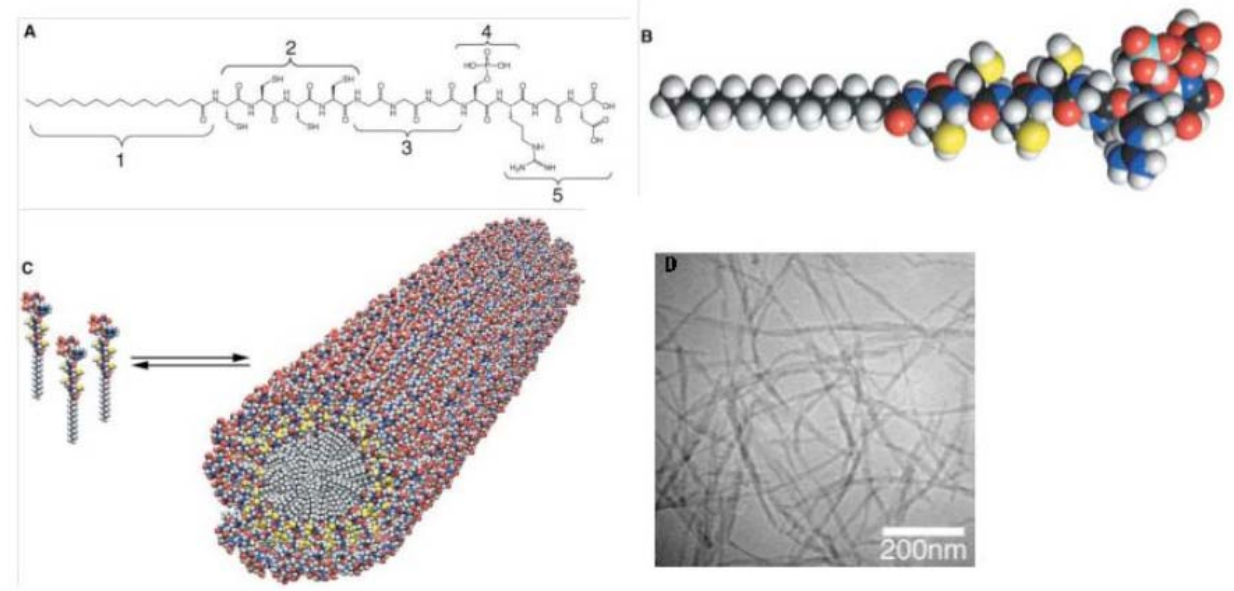

Fig. (4). Schematic illustrations of self-assembling nanofibers from peptide amphiphiles. Chemical structure (A) and molecular model (B) of the peptide amphiphile; schematic of the self-assembly of PA molecules into a cylindrical micelle (C); cryo-TEM of the fibers (D) From [44]. Reprinted with permission from AAAS.

approach that combined two oppositely charged PAs into a single self-assembled nanofiber at physiological $\mathrm{pH}$. This strategy may promote the use of self-assembling peptides in biomedical applications for in vitro or in vivo cell therapies.

The use of these self-assembling peptides has several limitations, such that the large-scale fabrication of a commercially viable peptide product can be expensive [48, 49]. In addition, the formation of mechanically stable 3D geometry is difficult because the nanofibers are formed through a number of non-covalent interactions. Moreover, the degradation of these nanofibers also remains a challenge. Nevertheless, the self-assembling nanofibers have advantages over preassembled devices, which require tissue excision to allow their insertion. Alternatively, peptide/PA solutions can be injected into an injured site, the gel in situ to fill the cavities at injury sites despite the geometrical shapes of the cavities. Self-assembly strategy eliminates the need for tissue excision and allows for the non-invasive introduction of biomaterials at injury sites. These features are highly favorable for clinical applications.

\subsection{Guidance Cues with Nanofibrous Scaffolds for Nerve Regeneration}

Neurons are functionally and anatomically polarized and display a high degree of subcellular polarity [50]. Directed cell migration and axonal guidance are particularly important during neural development because certain random signaling structures that are transplanted within the lesion site would lead to disorganized axon growth. Controlling the axonal orientation is a critical component in establishing signaling pathways and neuron connectivity after injury. Topographical and chemical guidance cues are widely used to achieve longitudinally oriented nerve tissue and direct axonal regrowth across nerve lesion sites [51-54]. 
Topographical features of the substrates can determine the direction of nerve growth because the developing neurons can "read" the physical properties of the local substrate in a contact-dependent manner. This guidance functions via a contact mechanism based on the directed locomotor response of cells to environmental anisotropy. Neurons extend their neurites along ridges or in parallel to the alignment of electrospun nanofibers and sometimes form longer neurites [16, $55,56]$. Moreover, neurites would turn at large angles for alignment to grooves [57]. Ferrari et al. [58] documented that neuronal polarization and contact guidance were based on a geometrical constraint of focal adhesion, which resulted in the angular modulation of the neural maturation and persistence. Moreover, the Rho-dependent kinase (ROCK)mediated contractility contributed to polarity selection during neuronal differentiation [58]. The contact guidance of axons on topographies with grooves/ridges is sizedependent; that is, the guidance efficiency is determined by the relationship between the axon diameter and groove/ridge width [59]. For example, Xenopus neurites grow parallel to grooves as shallow as $14 \mathrm{~nm}$ and as narrow as $1 \mu \mathrm{m}$, whereas hippocampal neurites grow parallel to deep, wide grooves but are perpendicular to shallow, narrow ones [57].

Aligned nanofibers are widely used to provide contact guidance to nerve cells, which are properly oriented along the aligned fiber direction and show elongated morphologies [16]. Newly regenerated neurites can be dynamically directed to grow parallel to the fiber alignment even when their initial orientation is different [18]. Stem cells display sensitivity to the topographical cues of substrates; this response may be transmitted to the nucleus by cytoskeletal-linked signaling pathways [60]. Stem cells from different sources show higher rates of neuronal differentiation on electrospun aligned nanofibers than on other scaffolds prepared from the same biomaterials $[61,62]$. This preference in neuronal differentiation may be associated with the substrate selectivity against oligodendrocytes and the substrate-mediated canonical $\mathrm{Wnt} / \beta$-catenin pathway [60]. Electrospinning is a powerful technique for preparing well-aligned nanofibers. However, this method cannot be used to encapsulate living cells because of the use of high mechanical and electrical energies. Recently, Zhang et al. [63] prepared extraordinarily long arrays of aligned nanofiber bundles by manually drawing an aqueous PA solution into a salty medium with a pipette. The aligned PA nanofibers are biodegradable, and cells can be incorporated at physiological temperatures to form monodomain gels of aligned cells and filaments for biological applications. These nanofibers provided directional guidance to regenerating axons and deliver proteins directionally over extended periods [64].

The growth cone at the tip of a growing axon can sense a gradient of guidance cues in the extracellular environment via filopodial and lamellar protrusions; correspondingly, this structure regulates its growth in a direction toward or away from the guidance cues [65]. Numerous studies have been conducted to identify the chemotactic factors involved and their functional mechanisms. Meanwhile, neuroscientists are attempting to construct stimuli that favor tissue regeneration [66]. The incorporation of chemotactic factors that can cause directional cell migration and directional axonal growth have particular importance and are of current interest in promoting nerve regeneration. Numerous studies have shown that the chemotropic gradients of ECM proteins, growth factors, and cytokines are vital in axonal targeting, dendritic growth, and synapse formation [67-70]. Taylor et al. [71] fabricated a substrate-bound laminin gradient on a uniform poly-L-lysine layer over distances of a few hundred micrometers. Axon specification of rat hippocampal neurons cultivated in vitro was oriented in the direction of the increasing laminin concentration. Moreover, the researchers found that a laminin gradient with a slope of $>0.06 \mu \mathrm{g} / \mathrm{mL} / \mu \mathrm{m}$ orients axon specification, whereas those with a slope of $<0.06 \mu \mathrm{g} / \mathrm{mL} / \mu \mathrm{m}$ show no effect [71]. Taylor et al. [71] bridged rat C3 lesions via an NT-3 gradient. The maximum axonal growth distance was $1 \mathrm{~mm}$ beyond the lesion, whereas a continuing gradient of NT-3 extended to 1-1.5 mm beyond this point. The concentration and concentration gradient of the neurotrophic factor vary among cells; the source of these factors may also be critical in directing axonal growth. In the model of a linear NGF concentration gradient by Cao [70], the minimum concentration gradient for effective guidance of PC12 cell neurite outgrowth is $133 \mathrm{ng} / \mathrm{mL} / \mathrm{mm}$; below this level, the guidance is ineffective. At an NGF concentration of 995 $\mathrm{ng} / \mathrm{mL}$, the PC12 cell receptors would be saturated, and the maximum effective distance for guidance would be limited to less than $7.5 \mathrm{~mm}$ [72]. Moreover, axonal growth over long distances may be not sustainable with only a trophic stimulus; the introduction of gradients of bioactive signals into biomaterial scaffolds is crucial to nerve regeneration. The immobilization of growth factors in specified locations within hydrogel networks is a widely used approach to generate gradients in biomaterials. Kapur et al. [73] immobilized NGF within poly(2-hydroxyethylmethacrylate) microporous gels with a gradient maker and showed that PC12 cell neurites can be guided up the gradient at an NGF concentration gradient of $357 \mathrm{ng} / \mathrm{mL} / \mathrm{mm}$. In another study by the same group [74], well-defined NGF and NT-3 concentration gradients were co-immobilized in a scaffold and showed a synergistic response in enhancing the directionality of the extending dendrites of DRG neurons. Multiple guidance cues can be presented in a spatially defined manner via special nanotechniques, and neurite growth can be synergistically guided by complex microenvironments that contain multiple molecular cues. For example, Li et al. [75] created a linear gradient of inhibitory chondroitin sulfate proteoglycan (CSPG) and/or permissive laminin-1 (LN). This linear gradient was generated as opposing double-cue gradients with varying slopes. DRG neurons strongly extended neurites toward regions of lower CSPG and higher LN concentrations.

\section{LOCAL ADMINISTRATION OF FUNCTIONAL MOLECULES}

\subsection{ECM Proteins and Growth Factors}

ECM proteins and soluble growth factors, which act as signaling molecules, have vital and complex roles in regulating cell division, survival, and neurite outgrowth during the embryonic and postnatal development of the nervous system [76]. ECM proteins, such as laminin and fibronetin, and growth factors, such as the nerve growth factor (NGF) [77, 78], neurotrophin-3 (NT-3) [71], and basic fibroblast growth factor (bFGF) [79], are known to promote neuronal survival 
and growth. Other growth factors involved in nerve regeneration include the vascular endothelial growth factors (VEGFs) [80], brain-derived neurotrophic factor (BDNF) [81], insulin-like growth factors (IGFs) [82], ciliary neurotrophic factors (CNTFs) [83, 84], and neurotrophic factor4/5 (NT-4/5) [85]. In their native state, these bioactive molecules are secreted by nerve target cells or surrounding glial cells. However, nervous system damage or disease generally interrupts the communication between nerve-cell bodies and their targets and disrupts the relationships between neurons and their supporting cells. The administration of exogenous bioactive molecules may be vital in directing and facilitating neuronal survival after injury. Polymer matrices have recently been the subject of considerable research as delivery vehicles for controlling drug-release profiles, prolonging the presence of drugs in circulation, and targeting drugs to a specific site for axon regeneration.

\subsubsection{Encapsulation of Proteins/Growth Factors into Po- lymeric Substrates}

Polymer microspheres/nanoparticles are common delivery devices used to treat injuries or medical disorders in the nervous system because of their ready encapsulation of various therapeutic agents, including oligonucleotides, peptides, proteins, and drugs. The release rate of an encapsulated agent can be controlled by tailoring the degradation rate of the microspheres, which are prepared from biodegradable polymers based on their composition and molecular weight [86]. Water-soluble proteins are encapsulated into the microspheres during preparation via the emulsion-solvent evaporation method [86, 87]. NGF has been demonstrated to maintain its bioactivity during controlled release over an extended period [86].However, the protein-release profile of this system is often marked by a prominent initial burst because of proteinpolymer phase separation and the subsequent protein integration into the polymer matrix. Meanwhile, most biodegradable polyesters, such as polylactic acid and poly(lactic-coglycolic acid) (PLGA), are bulk-eroding polymers that show non-linear and discontinuous erosion kinetics. Rui et al. [85] observed an initial release of $67.6 \% \pm 8.25 \%$ VEGF encapsulated in PLGA microspheres within the first $24 \mathrm{~h}$, followed by gradual release of approximately $0.34 \%$ per day for four weeks. The initial burst can be reduced, and zero-order release kinetics is achieved by surface-erosion polymers such as polyanhydrides to prepare the microspheres/nanoparticles [88]. Nerve regeneration can be enhanced by loading microspheres/nanoparticles within fibrin glue or 3D scaffolds, which are subsequently applied at the local nerve-injury site [89, 90]. The drug-loaded carriers are also fabricated into nerve-guidance conduits that retain the bioactivity of the released growth factor; these conduits can be surgically implanted for nerve-injury treatment [91]. The release of therapeutic agents can be induced by external stimuli, such as electrical and magnetic stimulation, thereby allowing for the precise and controlled delivery of these agents to the intended regenerating nerve environment $[92,93]$.

A polymer matrix can be used as an alternative delivery vehicle for signaling molecules. ECM proteins and growth factors can be incorporated within the walls or on the surface of the matrix during fabrication or after treatment. Polymer degradation triggers the release of growth factors. A com- mon approach is to fill the nerve conduit or $3 \mathrm{D}$ porous scaffold with various gels that are loaded with neurotrophic factors. Fibrin, collagen, gelatin, and laminin have been utilized as carriers [94-98]. Cross-linking is generally performed to minimize the diffusion of the growth factor from the matrix, thereby prolonging the presentation and maintaining the functional concentration of the growth factor. The bioactivity of the neurotrophic factor can be maintained for an extended period. Genipin is considerably less toxic than most of the commonly used synthetic cross-linking reagents (e.g., glutaraldehyde); this compound is extensively used as a natural cross-linker for proteins, collagen, gelatin, and chitosan [99]. The maintenance of a suitable concentration of the neurotrophic factor for an extended period is critical during nerve regeneration. In these systems, the release rate of the neurotrophic factor can be controlled by varying the genipin concentration [95]. Simultaneous administration of multiple neurotrophic factors may create a microenvironment that is more similar to the native environment, thereby exerting a synergistic effect on axonal growth. Madduri et al. [100] reported the synergistic effect of GDNF and NGF on axonal outgrowth from chicken embryonic dorsal root ganglia (DRG) in vitro and the enhanced early axonal regeneration in a $10 \mathrm{~mm}$ rat sciatic nerve gap model [101]. Such an approach may be an important prerequisite for the eventual establishment of functional connections with the target organ [98, $101,102]$.

\subsubsection{Incorporation of Proteins/Growth Factors onto Po- lymeric Substrates by Non-Covalent Interactions}

Bioactive molecules can be also be immobilized by noncovalent interactions, including charges, hydrophobicity, hydrogen bonding, or van der Waals forces [103]. One example is the heparin-containing delivery system for the controlled delivery of growth factors, which include high heparin-binding affinity growth factors, such as bFGF and EGF, as well as low heparin-binding affinity growth factors, such as NGF, BDNF, and NT-3. Heparin immobilization can preserve the biological activity of growth factors by preventing their early degradation. Neurotrophic factors immobilized in the heparin-contained gels/hydrogels can be locally released from the matrix to enhance neurite extension [104-106]. Sakiyama et al. [107] developed an affinity-based delivery system that consists of a bidomain peptide containing a transglutaminase substrate domain and a heparin-binding domain. The bioactivity of GDNF could be retained by this delivery system, as confirmed by enhanced neurite extension in vitro [108]. This delivery system also enhanced peripheral nerve regeneration [109].

\subsubsection{Incorporation of Proteins/Growth Factors onto Po- lymeric Substrates by Post-Modification}

Post-modification of the prefabricated scaffolds, particularly via surface modification with bioactive molecules, such as ECM proteins and short peptide fragments, is a simple yet efficient method to improve the biocompatibility and biological activity of scaffolds. The surface loading of target molecules can be performed by simple physical adsorption, layer-by-layer (LbL) assembly, and chemical immobilization. Patel et al. [110] showed that laminin and bFGF adsorbed on heparin-immobilized PLLA nanofibers enhances 
neurite outgrowth from DRG tissue. Most polysaccharides and proteins are polyelectrolytes, whose charges can be changed by adjusting the $\mathrm{pH}$. Thus, these biomolecules can be used to engineer surfaces by LbL self-assembly. Chitosan and gelatin are two widely used natural macromolecules for nerve-tissue engineering applications. In our previous study [111], we fabricated chitosan/gelatin polyelectrolyte multilayers (PEM) on PLLA electrospun nanofibers by LbL selfassembly. The PEM modification had no effects on the porous and fibrous morphology of the scaffold but significantly enhanced the neuron-matrix interactions by improving cell viability and neurite outgrowth [111]. Similarly, laminin could be immobilized on the electrospun fibers by LbL selfassembly, thereby creating a permissive microenvironment for nerve cells [111, 112].

\subsection{Peptides}

In addition to proteins of large molecular weight, the laminin-derived YIGSR and IKVAV peptide sequences have been shown to promote cell adhesion and neurite outgrowth, respectively [113-115]. Peptides have novel advantages over proteins because of their ease of manufacture, reproducibility with less potential lot-to-lot variability, and high stability under harsh processing conditions [116, 117]. 3D scaffolds or nerve conduits grafted with these specific peptides significantly improve neuronal adhesion and neurite outgrowth [118]. Direct anchoring of peptides with amino groups via zero-length cross-linking agents, such as carbodiimides, cause reduced bioactivity [119]. Therefore, a linking segment is required to increase the exposure of the anchoring peptides on the surface and allow their interaction with the seeded cells on the materials. A widely used and effective strategy is the introduction of flexible space chains such as polyethylene glycol or multi-methylene units, which have soft segments [120, 121]. Extended laminin-derived oligopeptides or relatively long cross-linking agents have shown potential in peptide grafting, such as sulfosuccinimidyl-4-( $N$-maleimidomethyl)cyclohexane-1-

carboxylate, which has an $11 \AA$ link space $[122,123]$. A number of recent studies have suggested that the binding sites, namely, the $\mathrm{N}$-terminus and $\mathrm{C}$-terminus, the linker length between the peptides, and the materials used affect the peptide bioactivity $[119,120,124-126]$. In a previous study [117], we directly anchored CSIKVAV and CYIGSR to lysine-capped PLLA. Multi-methylene units with different numbers of methylene groups $(2,5$, and 8$)$ served as the spacer. A higher number of peptides were grafted on the surface when the 5-methylene spacer was used; this phenomenon resulted in higher cell viability and longer neurites than the other two systems. The results indicate that a spacer with the appropriate length must be used to expose the functional groups and anchor the peptides.

\section{STEM CELLS FOR NERVE REGENERATION}

\subsection{Direct Use of Stem Cells for Nerve Regeneration}

Researchers have begun to investigate the potential applications of stem cells in nerve regeneration [127-129]. Stem cells generally have two significant advantages as compared with other cell sources for regenerative medicine: self-renewal and potency. Self-renewal is the ability to go through numerous cycles of cell division while maintaining the undifferentiated state. Potency is the capacity to differentiate into specialized cell types under appropriate conditions. Accumulated evidence has indicated the remarkable potential of transplanted stem cells in the nerve system in terms of possibly promoting functional recovery possibly, remodeling the injured tissue, and increasing the tissue plasticity [130]. Numerous stem cell types have been utilized as the seed cells for nerve regeneration; these cells include embryonic stem cells (ESCs), neural stem cells (NSCs), mesenchymal stem cells (MSCs), and induced pluripotent stem cells (iPSCs). Large quantities of stem cells are generally obtained by in vitro proliferation and transplanted to the injured lesion. Stem cells will differentiate into neurons and glial cells in vivo and re-establish new axonal connections between broken axons (Fig. 5).

Therapies for neural repair based on ESCs have advanced at a rapid rate according to their differentiation pluripotency and ability to propagate. Various methods have been exploited to induce ESCs into neural progenitor cells and nerve cells for the treatment of neurological diseases, such as depression, Parkinson's and Alzheimer's disease. In addition, ESCs are potential sources of cells for the replacement of dead nerve cells caused by acute injuries, such as traumatic brain injury and spinal cord injury. However, several concerns regarding ESCs challenge their application, including ethical, religious, and safety issues, such as ESC rejection and tumorigenicity risk [131].

NSCs are derived from the ectoderm layer and have the potential to become any cell type in the central nervous system, including neurons, astrocytes, and oligodendrocytes. Therefore, NSCs offer an alternative attractive method for regenerating lost or damaged nerve tissue after disease or injury. NSCs are mainly isolated from the hippocampus and sub-ventricular zone (SVZ) in the adult brain, as well as the spinal cord, which is a non-neurogenic region. In addition to experimental investigations in the laboratory, NSCs have been transplanted in the clinic to test their safety. In a clinical trial, all the twelve patients that received cell transplantation tolerated the treatment without any long-term complications related to the surgical procedure or the implantation of NSCs; one patient even manifested an improved clinical status [132].

Under certain conditions, MSCs can be induced to differentiate into nerve cells in vitro and in vivo in response to the nervous environment [133]. MSCs also promote functional recovery by producing trophic factors that induce survival and regeneration of host neurons when transplanted at sites of nerve injury [134]. In addition, MSCs exert an immunosuppressive effect in vitro and in vivo by acting on all immune effectors [135]. Therefore, MSCs have remarkable potential for promoting nerve repair. However, several studies have documented that bone marrow cells can dedifferentiate into neurons $[136,137]$.

Recently, interest in iPSCs has increased because of their excellent properties. Okano's group [138] has done extensive work on the application of iPSCs in nerve injury repair. In 2009, their group induced mouse iPSCs into NSCs/NPCs basing on conditions for experiments on mouse ESCs. In the subsequent years, the same group sequentially succeeded in 


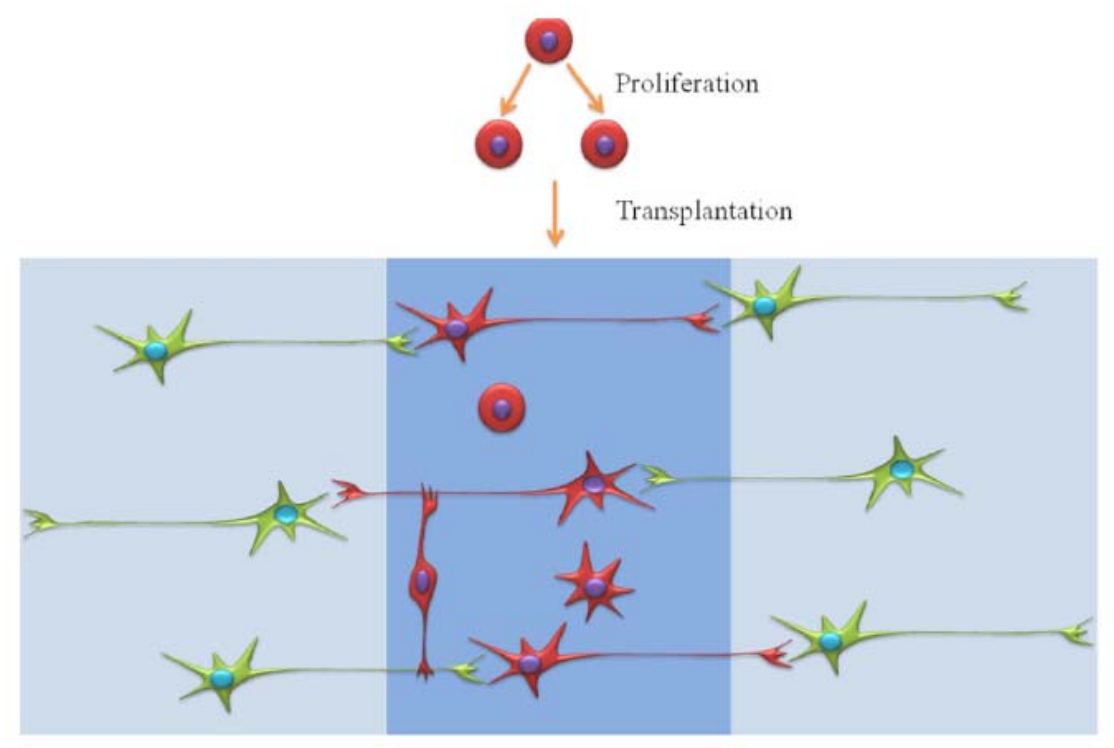

Fig. (5). Schematic diagram of the therapeutic mechanism with stem cells, including neurons to reestablish axonal connections and glial cells to remyelinate axons. Red: transplanted stem cells; green: host cells.

transplanting mouse iPSC-derived NSCs/NPCs into a mouse SCI model, transplanting human iPSC-derived stem cells into a mouse SCI model, and transplanting human iPSCderived NS/PCs into the marmoset SCI model. All these investigations documented that motor functions were restored for a long period of time without the development of tumors [138]. These findings were of great significance to the preclinical research of iPSCs for nerve regeneration.

However, the development of stem cells for nerve regeneration has several challenges. One issue is the optimization of experimental conditions for their directional differentiation into neuronal cells. Another concern is their specific differentiation. Pluripotency in certain stem cells could also limit the capacity to obtain a specific cell type. Undifferentiated cells can create tissues other than the desired types. For example, MSCs lack the voltage-gated ion channels necessary for the generation of action potentials; therefore, these cells may not actually be classified as true neurons [139]. Furthermore, the applied stem cells should not form tumors after transplantation. With the advanced understanding of their biological roles, the signals that induce particular neuronal differentiation, and the underlying mechanism at the molecular level, we believe that strategies can be developed in the future to manipulate these stem cells in situ and tailor them for nerve repair.

\subsection{Electrical Stimulation (ES) with Stem Cell Therapy for Nerve Regeneration}

Electrical activity is involved in various aspects of early neuronal development; this activity can alter several cell properties, such as differentiation, proliferation, adhesion, migration, and function [140]. ES can promote NGF-induced neurite outgrowth by increasing the NGF-induced phosphorylation of ERK1/2 and Egr1 gene expression [141]. Kimura et al. [142] reported that neural cell differentiation could be electrically induced to stimulate neurite extension in the absence of NGF. Meanwhile, Yamada et al. [143] reported that ES can drive embryonic stem cell differentiation toward neuronal lineages in a significantly shorter period than the use of growth factors to initiate cell differentiation. Preference toward astrocytes was documented by Matsumoto et al. [144] when ES was applied for the differentiation of mouse bone mesenchymal stem cells. In their study [144], ES enhanced neurogenin 2 expression via the $\beta$-catenin signaling pathway. In addition, ES promotes the regeneration of motor and sensory neurons [145], accelerates the regeneration of peripheral axons in the DRG [146], and extends the survival of axons in retinal ganglion cells [147]. Briefly, direct ES has been shown to improve nerve regeneration and functional recovery in animal models and in a small cohort of patients [148]. Liu et al. [149] indicated that the application of brief ES to newly transplanted embryonic neurons in the peripheral nerve could promote muscle re-innervation and function, as well as axon growth.

The construction of a local electrical environment can significantly improve functional recovery in nerve defect repair. For a large nerve defect, a conductive nerve graft must be used to bridge the two nerve stumps. Consequently, electrically conductive materials have attracted significant attention in scaffold construction. Polypyrrole (PPy) and polyaniline (PANI) are extensively studied conductive polymers in tissue engineering. The in vitro studies showed that PC12 cells on PPy films and PPy-coated nanofibers showed significantly increased neurite length under ES [150152]. The application of ES to nerve cells on conductive PANI-PCL-Gel nanofibrous scaffolds significantly enhanced cell proliferation and neurite outgrowth compared with cells on non-stimulated scaffolds [153]. Huang et al. [154] established an electrical environment by applying localized ES on a conductive PPy/chitosan scaffold to treat a $15 \mathrm{~mm}$ nerve defect in rats. Axonal regeneration and remyelination of the regenerated axons were significantly enhanced in the electrical environment [154]. Molecular tests indicated that ES upregulated the expression of S-100, BDNF, P0, and Par-3; this effect accelerated nerve regeneration and promoted functional recovery [154]. 
Carbon nanotubes (CNTs) with distinct electrical, mechanical, and surface properties have high potential for applications in tissue engineering. Controversies regarding the toxicity of CNTs remain, and challenges must first be addressed before these materials can be used in clinical applications. Numerous studies have been conducted to overcome these issues. Such research includes the chemical modification of CNTs to ensure their dissolution in aqueous media and biological functionalization to increase their biocompatibility and selectivity [155]. Chao et al. [156] reported that CNT-grafted poly(acrylic acid) could selectively induce human embryonic stem cells into neuron cells while maintaining excellent cell viability. Jin et al. [157] showed that a multi-walled CNT coating improved the neurite outgrowth of rat DRG neurons and promoted the expression of focal adhesion kinase in PC12 cells on poly(L-lactic acid-cocaprolactone) nanofibers. The enhancement of neuronsubstrate interactions after CNT incorporation may be attributed to the surface nanotopography of CNTs, which favors electrical shortcuts [158] and exhibits stronger signal transmission [159].

\section{CONCLUSIONS AND FUTURE PROSPECTS}

The anatomical, structural, and cellular responses to injury differ between the PNS and CNS. However, the importance and efficiency of their corresponding environments during regeneration have been shown in vitro and in vivo. To date, numerous nanotechniques have been used to engineer a growth-permissive environment for nerve regeneration, including the fabrication of a nanofibrous network with guidance cues that mimics natural ECM to support neuronal growth and axon extension, the functional molecular signal immobilization to mimic certain properties of natural ECM, and stem cell therapy.

Nerve regeneration is affected by multiple factors; thus, a complete reversal of the consequences of nerve injury by a single strategy is unlikely. A combination of different therapies may help overcome the multiple barriers to regeneration and provide synergistic effects to achieve maximum recovery. For example, electrical activity is involved in various aspects of early neuronal development; thus, other methods in addition to ES must be applied to determine the neuronal destiny. ${ }^{111}$ The immobilization of ECM proteins and growth factors onto aligned nanofibers could simulate the physical and biochemical properties of native matrix fibrils, thereby promoting highly efficient neurite outgrowth [93]. The restoration of neural populations at the lesion site is also critical because numerous neurons die after injury. Other cells can provide various functional molecules, such as antiinflammatory cytokines and neurotrophic factors, which benefit nerve regeneration. Therefore, cell transplantation should be considered to fabricate an engineering environment for nerve regeneration. Tissue engineering has a high potential of promoting nerve regeneration by enhancing the regeneration capability of neurons and providing permissive environments. With the development of neuroscience, materials science, materials engineering, and nanotechnology, significant breakthroughs in nerve regeneration will be achieved in the near future.

\section{CONFLICT OF INTEREST}

The authors confirm that this article content has no conflict of interest.

\section{ACKNOWLEDGEMENTS}

The authors thank for funding supports from the National Program on Key Basic Research Project (973 Program, 2014CB542205), Foundation for Distinguished Young Talents in Higher Education of Guangdong (Yq2013023), Pearl River Nova Program of Guangzhou (1317000404) and China Postdoctoral Science Foundation (2013M540684). The authors wish to acknowledge the support from the Hong Kong Scholars Program (XJ2012024) and the Leading Talents of Guangdong Province (87014002).

\section{REFERENCES}

[1] Wnald J, Sadowsky C, Spinal-cord injury. Lancet 2002; 359: 417.

[2] Chodobski A, Zink BJ, Szmydynger-Chodobska J. Blood-brain barrier pathophysiology in traumatic brain injury. Transl Stroke Res 2011; 2(4): 492-516.

[3] Zhang N, Yan H, Wen X. Tissue-engineering approaches for axonal guidance. Brain Res Brain Res Rev 2005; 49(1): 48-64.

[4] Kumaran AM, Sundar G, Thiam C. a review. Craniomaxillofac Trauma Reconstr 2015; 8(1): 31-41.

[5] Moulin P, Gohritz A, Meunzel J. Spinal cord injury. Still an interdisciplinary challenge (vol 43, pg 625, 2014). Orthopade 2014; 43(10): 929-929.

[6] Huang Y, Huang Y. Biomaterials and strategies for nerve regeneration. Artif Organs 2006; 30(7): 514-22.

[7] Smith L.A. Ma P. Nano-fibrous scaffolds for tissue engineering. Colloids Surf B Biointerfaces 2004; 39(3): 125-31.

[8] Ma PX. Biomimetic materials for tissue engineering. Adv Drug Deliv Rev 2008; 60(2): 184-98.

[9] Lu T, Li Y, Chen T. Techniques for fabrication and construction of three-dimensional scaffolds for tissue engineering. Int J Nanomedicine 2013; 8: 337-50.

[10] Dahlin R.L., Kasper FK, Mikos A. Polymeric nanofibers in tissue engineering. Tissue Eng Part B Rev 2011; 17(5): 349-64.

[11] He L., Liu B. Guan X, et al. Microstructure and properties of nanofibrous PCL-b-PLLA scaffolds for cartilage tissue engineering. Eur Cell Mater 2009; 18: 63-74.

[12] He L, Zhang Y, Liao, et al. Fabrication and characterization of poly (L-lactic acid) nanofibrous scaffolds with 3D controlled architecture by thermally induced phase separation from a ternary polymersolvent system. Polymer 2009; 50: 4128-38.

[13] O'Brien F, Harley B, Yannas I, Gibson L. The effect of pore size on cell adhesion in collagen-GAG scaffolds. Biomaterials 2005; 26(4): 433-41.

[14] Mukhatyar V, Salmeron-Sanchez M, Rudra S. et al. Role of fibronectin in topographical guidance of neurite extension on electrospun fibers. Biomaterials 2011; 32(16): 3958-68.

[15] Yang F, Murugan R, Ramakrishna S, et al. Fabrication of nanostructured porous PLLA scaffold intended for nerve tissue engineering. Biomaterials 2004; 25(10): 1891-900.

[16] He L, Liao S, Quan D, et al. Synergistic effects of electrospun PLLA fiber dimension and pattern on neonatal mouse cerebellum C17.2 stem cells. Acta Biomater 2010; 6(8): 2960-9.

[17] Chen M, Patra P, Lovett M, et al. Role of electrospun fibre diameter and corresponding specific surface area (SSA) on cell attachment. J Tissue Eng Regen Med 2009; 3(4): 269-79.

[18] Yang F, Murugan R, Wang S, Ramakrishna S. Electrospinning of nano/micro scale poly(L-lactic acid) aligned fibers and their potential in neural tissue engineering. Biomaterials 2005; 26: 2603

[19] Wang Y, Yao M, Zhou J, et al. The promotion of neural progenitor cells proliferation by aligned and randomly oriented collagen nanofibers through $\beta 1$ integrin/M APK signaling pathway. Biomaterials 2011; 32: 6737

[20] Bagher Z, Azami M, Ebrahimi-Barough S, et al. Differentiation of Wharton's Jelly-Derived Mesenchymal Stem Cells into Motor Neu- 
ron-Like Cells on Three-Dimensional Collagen-Grafted Nanofibers. Mol Neurobiol 2015.

[21] Li D, Xia Y. Direct fabrication of composite and ceramic hollow nanofibers by electrospinning. Nano Letters 2004; 4(5): 933-8.

[22] Prabhakaran M, J.R., Venugopal T, Chyan T, et al. Electrospun Biocomposite Nanofibrous Scaffolds for $\mathrm{N}$ eural Tissue Engineering. Tissue Engineering Part A 2008; 14(11): 1787-97.

[23] Nakaji-Hirabayashi T, Kato K, Iwata H. Improvement of Neural Stem Cell Survival in Collagen Hydrogels by Incorporating Laminin-Derived Cell Adhesive Polypeptides. Bioconjug Chem 2012; 23(2): 212-21.

[24] Jin G, Prabhakaran M, Kai D. et al. Electrospun photosensitive nanofibers: potential for photocurrent therapy in skin regeneration. Photochem Photobiol Sci 2013; 12(1): 124-34.

[25] Prabhakaran M, Vatankhah E, Ramakrishna S. Electrospun Aligned PHBV/Collagen Nanofibers as Substrates for Nerve Tissue Engineering. Biotechnol Bioeng 2013; 110(10): 2775-84.

[26] Kai D, Liow S, Loh X. Biodegradable polymers for electrospinning: Towards biomedical applications. Materials Science \& Engineering C-Materials for Biological Applications, 2014; 45: 659-70.

[27] Christopherson G, Song H, Mao H. The influence of fiber diameter of electrospun substrates on neural stem cell differentiation and proliferation. Biomaterials 2009; 30(4): 556-64.

[28] Wang J, Ye R, Wei Y. et al. The effects of electrospun TSF nanofiber diameter and alignment on neuronal differentiation of human embryonic stem cells. J Biomed Mater Res A 2012; 100(3): 63245.

[29] Chen M, Patra P, Warner S. et al. Role of fiber diameter in adhesion and proliferation of NIH 3 T3 fibroblasts on electrospun polycaprolactone scaffolds. Tissue Eng 2007; 13: 579.

[30] Garg T, Rath G, Goyal A. Biomaterials-based nanofiber scaffold: targeted and controlled carrier for cell and drug delivery. J Drug Target 2015; 23(3): 202-221.

[31] Zeng C, Xiong Y, Xie G. et al. Fabrication and evaluation of PLLA multichannel conduits with nanofibrous microstructure for the differentiation of NSCs in vitro. Tissue Eng Part A 2014; 20(5-6): 1038-48.

[32] Sun C, Jin X, Holzwarth J. et al. Development of channeled nanofibrous scaffolds for oriented tissue engineering. Macromol Biosci 2012; 12(6): 761-9.

[33] Zhang S. Emerging biological materials through molecular selfassembly. Biotechnol Adv 2002; 20: 321.

[34] Holmes T, de Lacalle S, Su X. et al. Extensive neurite outgrowth and active synapse formation on self-assembling peptide scaffolds. Proc Natl Acad Sci USA 2000; 97(12): 6728-33.

[35] Guo J, Su H, Zeng Y, et al. Reknitting the injured spinal cord by self-assembling peptide nanofiber scaffold. Nanomedicine 2007; 3(4): 311-21.

[36] Guo J, Leung K, Su H, et al. Self-assembling peptide nanofiber scaffold promotes the reconstruction of acutely injured brain. Nanomedicine 2009; 5(3): 345-51.

[37] Zhan X, Gao M, Jiang Y, et al. Nanofiber scaffolds facilitate functional regeneration of peripheral nerve injury. Nanomedicine 2013; 9(3): 305-15.

[38] Ellis-Behnke R, Liang Y, You S, et al. Nano neuro knitting: peptide nanofiber scaffold for brain repair and axon regeneration with functional return of vision. Proc Natl Acad Sci USA 2006; 103(13): 5054-9.

[39] Li Q, Chau Y. Neural differentiation directed by self-assembling peptide scaffolds presenting laminin-derived epitopes. J Biomed Mater Res A 2010; 94(3): 688-99.

[40] Zhang Z, Zheng Q, Wu Y. Compatibility of Neural Stem Cells with Functionalized Self-assembling Peptide Scaffold In vitro. Biotechnol Biopro Eng 2010; 15: 545.

[41] Cheng T, Chen M, Chang W, et al. Neural stem cells encapsulated in a functionalized self-assembling peptide hydrogel for brain tissue engineering. Biomaterials 2013; 34(8): 2005-16.

[42] Stupp S. Self-assembly and biomaterials. Nano Lett 2010; 10(12): 4783-6.

[43] Hartgerink J, Beniash E, Stupp S. Peptide-amphiphile nanofibers: a versatile scaffold for the preparation of self-assembling materials. Proc Natl Acad Sci USA 2002; 99(8): 5133-8.

[44] Hartgerink J, Beniash E, Stupp S. Self-assembly and mineralization of peptide-amphiphile nanofibers. Science 2001; 294(5547): 16848 .
[45] Niece K, Hartgerink J, Donners J, Stupp S. Self-assembly combining two bioactive peptide-amphiphile molecules into nanofibers by electrostatic attraction. J Am Chem Soc 2003; 125(24): 7146-7.

[46] Zou Z, Zheng Q, Wu Y. et al. Growth of rat dorsal root ganglion neurons on a novel self-assembling scaffold containing IKVAV sequence. J Biomed Mater Res A 2009; 29(7): 2099-2103.

[47] Silva G, Czeisler C, Niece K, et al. Selective differentiation of neural progenitor cells by high-epitope density nanofibers. Science 2004; 303(5662): 1352-5.

[48] Kyle S, Aggeli A, Ingham E, McPherson M. Recombinant selfassembling peptides as biomaterials for tissue engineering. Biomaterials 2010; 31(36): 9395-405.

[49] Wu E, Zhang S, Hauser C. Self-assembling peptides as cellinteractive scaffolds. Advanced Functional Materials 2012; 22(3): 456-68.

[50] Rasband M. The axon initial segment and the maintenance of neuronal polarity. Nat Rev Neurosci 2010; 11(8): 552-62.

[51] Krick K, Tammia M, Martin R, et al. Signaling cue presentation and cell delivery to promote nerve regeneration. Curr Opin Biotechnol 2011; 22(5): 741-6.

[52] Norman L, Stroka K, Aranda-Espinoza H. Guiding axons in the central nervous system: a tissue engineering approach. Tissue Eng Part B Rev 2009; 15(3): 291-305.

[53] Thiede-Stan N, Schwab M. Attractive and repulsive factors act through multi-subunit receptor complexes to regulate nerve fiber growth. J Cell Sci 2015; 128(14): 2403-14.

[54] Chiono V, Tonda-Turo C. Trends in the design of nerve guidance channels in peripheral nerve tissue engineering. Prog Neurobiol 2015; 131: 87-104.

[55] Yin J, Coutris N, Huang Y. Numerical study of axonal outgrowth in grooved nerve conduits. J Neural Eng 2012; 9(5): 056001.

[56] Daly W, Yao L, Abu-rub M, et al. The effect of intraluminal contact mediated guidance signals on axonal mismatch during peripheral nerve repair. Biomaterials 2012; 33(28): 6660-71.

[57] Rajnicek A, Britland S, McCaig C. Contact guidance of CNS neurites on grooved quartz: influence of groove dimensions, neuronal age and cell type. J Cell Sci 1997; 110 (Pt 23): 2905-13.

[58] Ferrari A, Cecchini M, Serresi M, et al. Neuronal polarity selection by topography-induced focal adhesion control. Biomaterials 2010; 31(17): 4682-94.

[59] Johansson F, Carlberg P, Danielsen N, et al. Axonal outgrowth on nano-imprinted patterns. Biomaterials 2006; 27(8): 1251-8.

[60] Lim S, Liu X, Song H, et al. The effect of nanofiber-guided cell alignment on the preferential differentiation of neural stem cells. Biomaterials 2010; 31(34): 9031-9.

[61] Mahairaki V, Lim S, Christopherson G, et al. Nanofiber matrices promote the neuronal differentiation of human embryonic stem cell-derived neural precursors in vitro. Tissue Eng Part A 2011; 17(5-6): 855-63.

[62] Bakhru S, Nain A, Highley C, et al. Direct and cell signalingbased, geometry-induced neuronal differentiation of neural stem cells. Integr Biol (Camb) 2011; 3(12): 1207-14.

[63] Zhang S, Greenfield M, Mata A, et al. A self-assembly pathway to aligned monodomain gels. Nat Mater 2010; 9(7): 594-601.

[64] Angeloni N, Bond C, Tang Y, et al. Regeneration of the cavernous nerve by Sonic hedgehog using aligned peptide amphiphile nanofibers. Biomaterials 2011; 32(4): 1091-101.

[65] Tessier-Lavigne M, Goodman C. The molecular biology of axon guidance. Science 1996; 274(5290): 1123-33.

[66] Sant S, Hancock M, Donnelly J, et al. Biomimetic Gradient Hydrogels for Tissue Engineering. Can J Chem Eng 2010; 88(6): 899911.

[67] McAllister A, Katz L, Lo D. Opposing roles for endogenous BDNF and NT-3 in regulating cortical dendritic growth. Neuron 1997; 18(5): 767-78.

[68] Genc B, Ozdinler P, Mendoza A, Erzurumlu R. A chemoattractant role for NT-3 in proprioceptive axon guidance. PLoS Biol 2004; 2(12): e403.

[69] Dertinger S, Jiang X, Li Z, et al. Gradients of substrate-bound laminin orient axonal specification of neurons. Proc Natl Acad Sci USA 2002; 99(20): 12542-7.

[70] Cotrufo T, Perez-Branguli F, Muhaisen A, et al. A signaling mechanism coupling netrin-1/deleted in colorectal cancer chemoattraction to SNARE-mediated exocytosis in axonal growth cones. J Neurosci 2011; 31(41): 14463-80. 
[71] Taylor L, Jones L, Tuszynski M, Blesch A. Neurotrophin-3 gradients established by lentiviral gene delivery promote short-distance axonal bridging beyond cellular grafts in the injured spinal cord. $\mathrm{J}$ Neurosci 2006; 26(38): 9713-21.

[72] Cao X, Shoichet M. Defining the concentration gradient of nerve growth factor for guided neurite outgrowth. Neuroscience 2001; 103(3): 831-40.

[73] Kapur T, Shoichet M. Immobilized concentration gradients of nerve growth factor guide neurite outgrowth. Journal of Biomedical Materials Research Part A 2004; 68A(2): 235-43.

[74] Moore K, MacSween M, Shoichet M. Immobilized concentration gradients of neurotrophic factors guide neurite outgrowth of primary neurons in macroporous scaffolds. Tissue Eng 2006; 12(2): 267-78.

[75] Li G, Liu J, Hoffman-Kim D. Multi-molecular gradients of permissive and inhibitory cues direct neurite outgrowth. Ann Biomed Eng 2008; 36(6): 889-904.

[76] Gordon $\mathrm{T}$. The role of neurotrophic factors in nerve regeneration. Neurosurg Focus, 2009; 26: E3.

[77] Tuszynski M, Murai K, Blesch A, et al. Functional characterization of NGF-secreting cell grafts to the acutely injured spinal cord. Cell Transplant 1997; 6(3): 361-8.

[78] Zhou F, Walzer M, Wu Y, et al. Neurotrophins support regenerative axon assembly over CSPGs by an ECM-integrin-independent mechanism. J Cell Sci 2006; 119(Pt 13): 2787-96.

[79] Jungnickel J, Haase K, Konitzer J, et al. Faster nerve regeneration after sciatic nerve injury in mice over-expressing basic fibroblast growth factor. J Neurobiol 2006; 66(9): 940-948.

[80] Rosenstein J, Krum J, Ruhrberg C. VEGF in the nervous system. Organogenesis 2010; 6(2): 107-14.

[81] Lu P, Jones L, Tuszynski M. BDNF-expressing marrow stromal cells support extensive axonal growth at sites of spinal cord injury. Exp Neurol 2005; 191(2): 344-60

[82] Kilic A, Ojo B, Rajfer R, et al. Effect of white adipose tissue flap and insulin-like growth factor-1 on nerve regeneration in rats. Microsurgery $2013 ; 33(5)$ : 367-75.

[83] Sendtner M, Götz R, Holtmann B, Thoenen H. Endogenous ciliary neurotrophic factor is a lesion factor for axotomized motoneurons in adult mice. J Neurosci 1997; 17: 6999.

[84] McCallister W, McCallister E, Dubois B, Trumble T. Regeneration along intact nerves using nerve growth factor and ciliary neurotrophic factor. J Reconstr Microsurg 2004; 20(6): 473-81.

[85] De Wit J, Eggers R, Evers R, et al. Long-term adeno-associated viral vector-mediated expression of truncated TrkB in the adult rat facial nucleus results in motor neuron degeneration. J Neurosci 2006; 26(5): 1516-30.

[86] Cao X, Schoichet M. Delivering neuroactive molecules from biodegradable microspheres for application in central nervous system disorders. Biomaterials 1999; 20(4): 329-39.

[87] Rui J, Dadsetan M, Runge M, et al. Controlled release of vascular endothelial growth factor using poly-lactic-co-glycolic acid microspheres: In vitro characterization and application in polycaprolactone fumarate nerve conduits. Acta Biomater 2012; 8(2): 511-8.

[88] Gopferich A, Tessmar J. Polyanhydride degradation and erosion. Adv Drug Deliv Rev 2002; 54(7): 911-31

[89] Wood M, Kim H, Bilbily A, et al. GDNF released from microspheres enhances nerve regeneration after delayed repair. Muscle Nerve 2012; 46(1): 122-4.

[90] de Boer R, Borntraeger A, Knight A, et al. Short- and long-term peripheral nerve regeneration using a poly-lactic-co-glycolic-acid scaffold containing nerve growth factor and glial cell line-derived neurotrophic factor releasing microspheres. J Biomed Mater Res A 2012; 100A(8): 2139-2146.

[91] Yang Y, De Laporte L, Rives C, et al. Neurotrophin releasing single and multiple lumen nerve conduits. J Control Release 2005; 104(3): 433-46.

[92] Cho Y, Shi R, Ivanisevic A, Borgens R. A mesoporous silica nanosphere-based drug delivery system using an electrically conducting polymer. Nanotechnology 2009; 20(27): 275102.

[93] Ciofani G, Raffa V, Menciassi A, et al. Magnetic alginate microspheres: system for the position controlled delivery of nerve growth factor. Biomed Microdevices 2009; 11(2): 517-27.

[94] Moore A, Wood M, Chenard K, et al. Controlled delivery of glial cell line-derived neurotrophic factor enhances motor nerve regeneration. J Hand Surg Am 2010; 35(12): 2008-17.
[95] Chang C. Effects of nerve growth factor from genipin-crosslinked gelatin in polycaprolactone conduit on peripheral nerve regeneration-in vitro and in vivo. J Biomed Mater Res A 2009; 91 A: 586.

[96] Lee A, Yu V, Lowe J, et al. Controlled release of nerve growth factor enhances sciatic nerve regeneration. Exp Neurol 2003; 184(1): 295-303

[97] Willerth S, Rader A, Sakiyama-Elbert S. The effect of controlled growth factor delivery on embryonic stem cell differentiation inside fibrin scaffolds. Stem Cell Res 2008; 1(3): 205-18.

[98] Madduri S, Feldman K, Tervoort T, et al. Collagen nerve conduits releasing the neurotrophic factors GDNF and NGF. J Control Release 2010; 143(2): 168-74.

[99] Elzoghby A, El-Fotoh W, Elgindy N. Casein-based formulations as promising controlled release drug delivery systems. J Control Release 2011; 153(3): 206-16.

[100] Madduri S, Papaloizos M, Gander B. Synergistic effect of GDNF and NGF on axonal branching and elongation in vitro. Neuroscience Res 2009; 65(1): 88-97.

[101] Madduri S, di Summa P, Papaloizos M, et al. Effect of controlled co-delivery of synergistic neurotrophic factors on early nerve regeneration in rats. Biomaterials 2010; 31(32): 8402-8409.

[102] Lu P, Wang Y, Graham L, et al. Long-distance growth and connectivity of neural stem cells after severe spinal cord injury. Cell 2012; 150(6): 1264-73.

[103] Wang N, von Recum H. Affinity-based drug delivery. Macromol Biosci, 2011; 11(3): 321-32.

[104] Sakiyama-Elbert S, Hubbell J. Controlled release of nerve growth factor from a heparin-containing fibrin-based cell ingrowth matrix. J Control Release 2000; 69(1): 149-158

[105] Taylor S, McDonald J, Sakiyama-Elbert S. Controlled release of neurotrophin-3 from fibrin gels for spinal cord injury. J Control Release 2004; 98(2): 281-294.

[106] Freudenberg U, Hermann A, Welzel P, et al. A star-PEG-heparin hydrogel platform to aid cell replacement therapies for neurodegenerative diseases. Biomaterials 2009; 30(28): 5049-60.

[107] Sakiyama S, Schense J, Hubbell J. Incorporation of heparinbinding peptides into fibrin gels enhances neurite extension: an example of designer matrices in tissue engineering. FASEB J 1999; 13: 2214

[108] Wood M, Borschel G, Sakiyama-Elbert S. Controlled release of glial-derived neurotrophic factor from fibrin matrices containing an affinity-based delivery system. Journal of Biomedical Materials Research Part A 2009; 89A(4): 909-918.

[109] Wood M, Moore A, Hunter D, et al. Affinity-based release of glialderived neurotrophic factor from fibrin matrices enhances sciatic nerve regeneration. Acta Biomaterialia 2009; 5(4): 959-968.

[110] Patel S, Kurpinski K, Quigley R, et al. Bioactive nanofibers: Synergistic effects of nanotopography and chemical signaling on cell guidance. Nano Letters 2007; 7(7): 2122-8.

[111] He L, Shi Y, Han Q, et al. Surface modification of electrospun nanofibrous scaffolds via polysaccharide-protein assembly multilayer for neurite outgrowth. J Mater Chem 2012; 22(26): 1318713196.

[112] He L, Tang S, Prabhakaran M, et al. Surface modification of PLLA nano-scaffolds with laminin multilayer by LbL assembly for enhancing neurite outgrowth. Macromol Biosci 2013; 13(11): 1601-9.

[113] Kleinman H, Weeks B, Cannon F, et al. Identification of a $110 \mathrm{kD}$ nonintegrin cell surface laminin-binding protein which recognizes an A-chain neurite-promoting peptide. Arch Biochem Bio-phys 1991; 290: 320.

[114] Sephel G, Tashiro K, Sasaki M, et al. Laminin A chain synthetic peptide which supports neurite outgrowth. Bio-chem Biophys Res Commun 1989; 162: 821.

[115] Shaw D, Shoichet M. Toward spinal cord injury repair strategies: peptide surface modification of expanded poly(tetrafluoroethylene) fibers for guided neurite outgrowth in vitro. J Craniofac Surg 2003; 14(3): 308-16

[116] Hersel U, Dahmen C, Kessler H. RGD modified polymers: biomaterials for stimulated cell adhesion and beyond. Biomaterials 2003 24(24): 4385-415.

[117] He L, Liao S, Quan D, et al. The influence of laminin-derived peptides conjugated to Lys-capped PLLA on neonatal mouse cerebellum C17.2 stem cells. Biomaterials 2009; 30(8): 1578-86.

[118] Yu L, Kazazian K, Shoichet M. Peptide surface modification of methacrylamide chitosan for neural tissue engineering applications. J Biomed Mater Res A 2007; 82A(1): 243-55. 
[119] Massia S, Holecko M, Ehteshami G. In vitro assessment of bioactive coatings for neural implant applications. J Biomed Mater Res A 2004; 68A(1): 177-86.

[120] Santiago L, Nowak R, Rubin J, Marra K. Peptide-surface modification of poly(caprolactone) with laminin-derived sequences for adipose-derived stem cell applications. Biomaterials 2006; 27(15): 2962-9.

[121] Bech L, Meylheuc T, LepoittevinB. Chemical surface modification of poly(ethyleneterephthalate) fibers by aminolysis and grafting of carbohy-drates. J Polym Sci Part A: Polym Chem 2007; 45: 2172.

[122] Yu T, Shoichet M. Guided cell adhesion and outgrowth in peptidemodified channels for neural tissue engineering. Biomaterials 2005; 26(13): 1507-14.

[123] Levesque S, Shoichet M. Synthesis of cell-adhesive dextran hydrogels and macroporous scaffolds. Biomaterials 2006; 27(30): 527785.

[124] Mann B, Gobin A, Tsai A, et al. Smooth muscle cell growth in photopolymerized hydrogels with cell adhesive and proteolytically degradable domains: synthetic ECM analogs for tissue engineering. Biomaterials 2001; 22(22): 3045-51.

[125] Suzuki M, Itoh S, Yamaguchi I, et al. Tendon chitosan tubes covalently coupled with synthesized laminin peptides facilitate nerve regeneration in vivo. J Neurosci Res 2003; 72(5): 646-59.

[126] Duan X, McLaughlin C, Griffith M, Sheardown H. Biofunctionalization of collagen for improved biological response: Scaffolds for corneal tissue engineering. Biomaterials 2007; 28(1): 78-88.

[127] Grochmal J, Midha R. Recent Advances in Stem Cell-Mediated Peripheral Nerve Repair. Cells Tissues Organs 2014; 200(1): 1322.

[128] Schroeder J, Kueper J, Leon K. Stem cells for spine surgery. World Journal of Stem Cells, 2015; 7(1): 186-94.

[129] Khalifian S, Sarhane K, Tammia M, et al. Stem Cell-Based Approaches to Improve Nerve Regeneration: Potential Implications for Reconstructive Transplantation? Arch Immunol Ther Exp (Warsz) 2015; 63(1): 15-30

[130] Ramer L, Ramer M, Bradbury E. Restoring function after spinal cord injury: towards clinical translation of experimental strategies. Lancet Neurol 2014; 13(12): 1241-56.

[131] Lodi D, Iannitti T, Palmieri B. Stem cells in clinical practice: applications and warnings. J Exp Clin Cancer Res 2011; 30.

[132] Glass J, Boulis N, Johe K, et al. Lumbar intraspinal injection of neural stem cells in patients with amyotrophic lateral sclerosis: results of a phase I trial in 12 patients. Stem Cells 2012; 30(6): 114451 .

[133] Liu Z, Zhuge Y, Velazquez O. Trafficking and differentiation of mesenchymal stem cells. J Cell Biochem 2009; 106(6): 984-91.

[134] Crigler L, Robey R, Asawachaicharn A, et al. Human mesenchymal stem cell subpopulations express a variety of neuro-regulatory molecules and promote neuronal cell survival and neuritogenesis. Exp Neurol 2006; 198(1): 54-64.

[135] Tyndall A, Walker U, Cope A, et al. Immunomodulatory properties of mesenchymal stem cells: a review based on an interdisciplinary meeting held at the Kennedy Institute of Rheumatology Division, London, UK, 31 October 2005. Arthritis Res Ther 2007; 9(1).

[136] Terada N, Hamazaki T, Oka M, et al. Bone marrow cells adopt the phenotype of other cells by spontaneous cell fusion. Nature 2002; 416(6880): 542-5.

[137] Ying Q, Nichols J, Evans E, Smith A. Changing potency by spontaneous fusion. Nature 2002; 416(6880): 545-8.

[138] Okano H, Yamanaka S. iPS cell technologies: significance and applications to CNS regeneration and disease. Molecular Brain 2014; 7 .

[139] Hofstetter C, Schwarz E, Hess D, et al. Marrow stromal cells form guiding strands in the injured spinal cord and promote recovery. Proc Natl Acad Sci USA 2002; 99(4): 2199-2204.
[140] Spitzer N. Electrical activity in early neuronal development. Nature 2006; 444(7120): 707-12.

[141] Chang Y, Hsu C, Lin C, et al. Electrical stimulation promotes nerve growth factor-induced neurite outgrowth and signaling. Biochim Biophys Acta 2013; 1830(8): 4130-6.

[142] Kimura K, Yanagida Y, Haruyama T, et al. Gene expression in the electrically stimulated differentiation of PC12 cells. J Biotechnol 1998; 63(1): 55-65.

[143] Yamada M, Tanemura K, Okada S, et al. Electrical stimulation modulates fate determination of differentiating embryonic stem cells. Stem Cells, 2007; 25(3): 562-70.

[144] Matsumoto M, Imura T, Fukazawa T, et al. Electrical stimulation enhances neurogenin 2 expression through $\beta$-catenin signaling pathway of mouse bone marrow stromal cells and intensifies the effect of cell transplantation on brain injury. Neurosci Lett 2013 533: 71 .

[145] Geremia N, Gordon T, Brushart T, et al. Electrical stimulation promotes sensory neuron regeneration and growth-associated gene expression. Exp Neurol 2007; 205(2): 347-359.

[146] Udina E, Furey M, Busch S, et al. Electrical stimulation of intact peripheral sensory axons in rats promotes outgrowth of their central projections. Exp Neurol 2008; 210(1): 238-47.

[147] Goldberg J, Espinosa J, Xu Y, Davidson N, Kovacs GT, Barres B Retinal ganglion cells do not extend axons by default: promotion by neurotrophic signaling and electrical activity. Neuron 2002; 33: 689.

[148] Khuong H, Midha R. Advances in Nerve Repair. Curr Neurol Neurosci Rep 2013; 13(1).

[149] Liu Y, Grumbles R, Thomas C. Electrical stimulation of embryonic neurons for 1 hour improves axon regeneration and the number of reinnervated muscles that function. J Neuropathol Exp Neurol 2013; 72(7): 697-707.

[150] Schmidt C, Shastri V, Vacanti J, Langer R. Stimulation of neurite outgrowth using an electrically conducting polymer. Proc Natl Acad Sci USA 1997; 94: 8948.

[151] Xie J, MacEwan M, Willerth S, et al. Conductive core-sheath nanofibers and their potential application in neural tissue engineering. Adv Funct Mater 2009; 19(14): 2312-8.

[152] Lee J, Bashur C, Goldstein A, Schmidt C. Polypyrrole-coated electrospun PLGA nanofibers for neural tissue applications. Biomaterials 2009; 30(26): 4325-35.

[153] Ghasemi-Mobarakeh L, Prabhakaran M, Morshed M, et al. Electrical Stimulation of Nerve Cells Using Conductive Nanofibrous Scaffolds for Nerve Tissue Engineering. Tissue Engineering Part A 2009; 15(11): 3605-19.

[154] Huang J, Lu L, Zhang J, et al. Electrical Stimulation to Conductive Scaffold Promotes Axonal Regeneration and Remyelination in a Rat Model of Large Nerve Defect. Plos One 2012; 7(6).

[155] Hwang J, Shin U, Jang W, et al. Biofunctionalized carbon nanotubes in neural regeneration: a mini-review. Nanoscale 2013; 5(2): 487-97.

[156] Chao T, Xiang S, Chen C, et al. Carbon nanotubes promote neuron differentiation from human embryonic stem cells. Biochem Biophys Res Commun 2009; 384(4): 426-30.

[157] Jin G, Kim M, Shin U, Kim H. Neurite outgrowth of dorsal root ganglia neurons is enhanced on aligned nanofibrous biopolymer scaffold with carbon nanotube coating. Neurosci Lett 2011; 501(1): $10-4$

[158] Cellot G, Cilia E, Cipollone S, et al. Carbon nanotubes might improve neuronal performance by favouring electrical shortcuts. Nat Nanotechnol 2009; 4(2): 126-33.

[159] Lovat V, Pantarotto D, Lagostena L, et al. Carbon nanotube substrates boost neuronal electrical signaling. Nano Lett 2005; 5(6) 1107-10. 